\title{
Acrolein Disrupts Tight Junction Proteins and Causes Endoplasmic Reticulum Stress-Mediated Epithelial Cell Death Leading to Intestinal Barrier Dysfunction and Permeability
}

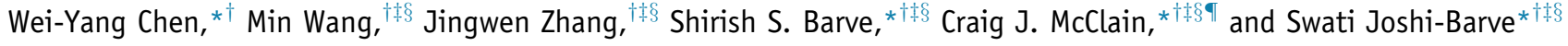

From the Departments of Pharmacology and Toxicology* and Medicine ${ }^{\ddagger}$, Alcohol Research Center ${ }^{\dagger}$, Hepatobiology and Toxicology Center ${ }^{\S}$, University of Louisville, Louisville; and the Department of Medicine, ${ }^{\pi}$ Robley Rex Veterans Affairs Medical Center, Louisville, Kentucky

\begin{abstract}
Accepted for publication
August 11, 2017.

Address correspondence to Swati Joshi-Barve, Ph.D., Departments of Medicine, and Pharmacology and Toxicology, University of Louisville, $505 \mathrm{~S}$. Hancock St., Room 505 CTRB, Louisville, KY 40202. E-mail: s0josh01@1ouisville.edu.
\end{abstract}

\begin{abstract}
Increasing evidence suggests that environmental and dietary factors can affect intestinal epithelial integrity leading to gut permeability and bacterial translocation. Intestinal barrier dysfunction is a pathogenic process associated with many chronic disorders. Acrolein is an environmental and dietary pollutant and a lipid-derived endogenous metabolite. The impact of acrolein on the intestine has not been investigated before and is evaluated in this study, both in vitro and in vivo. Our data demonstrate that oral acrolein exposure in mice caused damage to the intestinal epithelial barrier, resulting in increased permeability and subsequently translocation of bacterial endotoxin-lipopolysaccharide into the blood. Similar results were seen in vitro using established Caco-2 cell monolayers wherein acrolein decreased barrier function and increased permeability. Acrolein also caused the down-regulation and/or redistribution of three representative tight junction proteins (ie, zonula occludens-1, 0ccludin, Claudin1) that critically regulate epithelial paracellular permeability. In addition, acrolein induced endoplasmic reticulum stress-mediated death of epithelial cells, which is an important mechanism contributing to intestinal barrier damage/dysfunction, and gut permeability. Overall, we demonstrate that exposure to acrolein affects the intestinal epithelium by decrease/redistribution of tight junction proteins and endoplasmic reticulum stress-mediated epithelial cell death, thereby resulting in loss of barrier integrity and function. Our findings highlight the adverse consequences of environmental and dietary pollutants on intestinal barrier integrity/function with relevance to gut permeability and the development of disease. (Am J Pathol 2017, 187: 2686-2697; https://doi.org/10.1016/j.ajpath.2017.08.015)
\end{abstract}

It is increasingly clear from clinical and experimental evidence that intestinal epithelial barrier dysfunction (leaky gut) can predispose to or enhance a variety of chronic inflammatory intestinal and nonintestinal disorders, such as diabetes, inflammatory bowel disease (IBD), alcoholic liver disease, and autoimmune diseases, and so forth. ${ }^{1-3}$ Intestinal epithelial barrier function is critical for selective gut permeability that limits the entry of bacteria and pathologic bacterial components (eg, lipopolysaccharide; LPS) into the bloodstream, which, in turn, can trigger inflammatory responses and cause tissue injury. Intestinal barrier function is maintained primarily by a monolayer of epithelial cells sealed together by intercellular junction complexes. $^{4,5}$ Intestinal epithelial homeostasis is established by an equilibrium between cell proliferation and cell death, and dysregulated or excessive epithelial cell death greatly impairs barrier integrity. ${ }^{6}$ Increased epithelial cell apoptosis is suggested to play

Supported by NIH grants K01ES017105 (S.J.-B.), R01AA024405

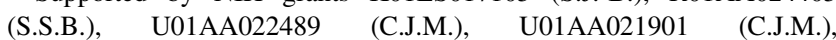
U01AA021893 (C.J.M.), R01AA018869 (C.J.M.), and R01AA023681 (C.J.M.) a Department of Veterans Affairs grant (C.J.M.), a Department of Defense grant (C.J.M.), an Institutional Development Award (IDeA) from the NIH National Institute of General Medical Sciences grant P20GM113226 and NIH National Institute on Alcohol Abuse and Alcoholism award P50AA024337 (C.J.M.).

The content is solely the responsibility of the authors and does not necessarily represent the official views of the NIH.

Disclosures: None declared. 
a pathogenic role in human IBD, including Crohn disease and ulcerative colitis. $^{7-9}$ The epithelial tight junctions that control paracellular permeability are complex structures composed of the tight junction proteins (TJPs), such as transmembrane proteins (eg, occludin and claudins), and peripheral membrane proteins [eg, zonula occludens-1 (ZO-1)]. The localization and interactions of TJPs are critical in maintaining intestinal barrier integrity; hence, alterations in TJPs are associated with changes in intestinal permeability.

Studies show that environmental pollutants, ${ }^{10}$ cigarette smoking, ${ }^{11,12}$ and dietary factors ${ }^{10}$ can notably alter intestinal permeability in association with various diseases. Acrolein, a reactive unsaturated aldehyde, is a common combustion-derived environmental pollutant and a main component of cigarette smoke. ${ }^{13}$ In addition, certain food substances are estimated to be important sources of acrolein; these include fried potato chips or French fries, donuts, wine, whiskey, and cheese. ${ }^{14}$ Because acrolein is a product of lipid peroxidation and glucose oxidation, high concentrations are generated by cooking, frying, and reheating of fats, oils, and sugars. ${ }^{15}$ Hence, fried fatty foods and charred meats represent significant dietary acrolein sources, which may be underestimated. ${ }^{16}$ The maximal daily human consumption of unsaturated aldehydes such as acrolein is estimated to be nearly $5 \mathrm{mg} / \mathrm{kg}$. ${ }^{17}$ Oral intake of acrolein can disrupt hepatic/metabolic and cardiovascular functions in mice ${ }^{17-19}$; however, although ingested acrolein is highly likely to affect the gastrointestinal system, its effects on the intestine have not been investigated. Our study shows that at concentrations comparable with human consumption, acrolein acts as a pathologic factor and impairs intestinal barrier function leading to enhanced gut permeability through mechanisms involving dysregulation of intestinal TJPs and epithelial cell death.

\section{Materials and Methods}

\section{Reagents}

Chemicals, acrolein, and $\beta$-actin antibody were purchased from Sigma-Aldrich (St. Louis, MO). Cell culture supplies and antibodies for Claudin-1, Occludin, and ZO-1 were obtained from Invitrogen (Carlsbad, CA). Acrolein Ne-(3-formyl-3,4dehydropiperidino) (FDP)-lysine antibody was purchased from Abcam (Cambridge, MA), and antibodies for activating transcription factor-3 (ATF3), activating transcription factor-4 (ATF4), CCAAT/enhancer-binding protein homologous protein (CHOP), protein kinase RNA-like endoplasmic reticulum kinase (PERK), phospho-PERK, and caspase-3 were from Cell Signaling Technology, Inc. (Beverly, MA).

\section{Animal Studies}

All experimental protocols were conducted under approval from the University of Louisville Institutional Animal Care and Use Committee in accordance with the NIH Office of Laboratory Animal Welfare Guidelines. Male C57BL/6J mice (10 weeks of age) were obtained from The Jackson Laboratories (Bar Harbor,
ME). They were maintained at $24^{\circ} \mathrm{C}$ with a 12 hours: 12 hours light/dark cycle and had free access to normal chow diet and tap water for 5 days before the start of the experiment. Acrolein (5 $\mathrm{mg} / \mathrm{kg}$ body weight) was administered by three consecutive oral gavages, separated by a time interval of 12 hours between each gavage; mice in the control group were given water by gavage in place of acrolein.

\section{Cell Culture}

Caco-2 cells (human colon carcinoma cells) were obtained from ATCC (Manassas, VA) and were cultured in Eagle's minimal essential medium supplemented with $100 \mathrm{U} / \mathrm{mL}$ penicillin, 100 $\mu \mathrm{g} / \mathrm{mL}$ streptomycin, and $10 \%$ fetal bovine serum at $37^{\circ} \mathrm{C}$ in a $5 \% \mathrm{CO}_{2}$ environment. To establish the in vitro model of the intestinal epithelial monolayer, Caco-2 cells were grown on commercial cell culture Transwell inserts (membrane area 0.33 $\mathrm{cm}^{2}$, pore size $0.4 \mu \mathrm{m}$; Corning, Corning, NY) for 21 days, during which time they undergo a process of spontaneous differentiation in culture and fully differentiate into mature enterocytes that simulate the intestinal epithelial cell barrier. ${ }^{20} \mathrm{~A}$ stable measurement of transepithelial electrical resistance (TEER) over 3 days was used as an indicator of a wellestablished differentiated Caco-2 cell monolayer.

\section{TEER}

Intestinal epithelial barrier integrity of established Caco-2 monolayers was assessed by measuring TEER with an epithelial volt ohmmeter (World Precision Instruments, Sarasota, FL). ${ }^{20}$

\section{In Vivo Intestinal Permeability Assay}

Mice were orally exposed to acrolein (or water as control) as described above. Three hours after the last gavage, mice were orally given fluorescein isothiocyanate-dextran with average molecular weight of 3000 to $5000 \mathrm{Da}$ (FD-4; Sigma-Aldrich) in saline $(500 \mathrm{mg} / \mathrm{kg}$ body weight, $125 \mathrm{mg} / \mathrm{mL}) .{ }^{21}$ After 3 hours, animals were euthanized, and serum was isolated. The serum was analyzed for FD-4 concentration using a fluorescence spectrophotometer at an excitation wavelength of $485 \mathrm{~nm}$ and an emission wavelength of $530 \mathrm{~nm}$.

\section{In Vitro Barrier Permeability Assay}

For intestinal epithelial barrier permeability assessment, FD4 was added to the apical side of the Caco- 2 monolayer Transwell inserts and incubated for 30 minutes. FD-4 leakage into the basal medium was measured with the use of a microplate fluorescence reader with an excitation wavelength of $485 \mathrm{~nm}$ and an emission wavelength of $530 \mathrm{~nm} .{ }^{22}$

\section{Serum Endotoxin Assay}

To assess intestinal permeability and translocation of bacterial products in vivo, LPS levels were determined in mouse sera 
samples with the use of the limulus amoebocyte lysate assay (QCL-1000; Whittaker Bio Inc., Walkersville, MD). Endotoxin concentrations were expressed in endotoxin units per milliliter.

\section{Serum IFABP Assay}

To assess intestinal epithelial cell damage, serum levels of intestinal fatty acid binding protein (IFABP) were measured by enzyme-linked immunosorbent assay (Aviva Systems, San Diego, CA) in accordance with the manufacturer's instructions. Serum was diluted 1:4 and added to a 96-well plate precoated with an antibody specific for IFABP.

The absorbance levels were measured immediately using a microplate spectrophotometer at $450 \mathrm{~nm}$.

\section{Acrolein Adducts Assay}

Ileum sections ( $5 \mu \mathrm{mol} / \mathrm{L}$ thick) and Caco- 2 cells grown on Transwells were fixed, stained with polyclonal rabbit antibodies specific for acrolein FDP-lysine adducts, and examined by light microscopy. Quantification was done with the use of the MetaMorph Microscopy Automation and Image Analysis Software version 6.1 (Molecular Devices, Sunnyvale, CA) by calculating percentage of positive (based on the average intensity of the field-of-view) microscope fields from 10 images per sample. ${ }^{23}$

\section{Cell Viability-MTT Assay}

Cell survival/cell death was measured in treated cells by the MTT (3-(4,5-dimethylthiazol-2-yl)-2,5-diphenyltetrazolium bromide) assay as described. ${ }^{24}$

\section{Cell Death by TUNEL Staining}

Cell death was assessed by terminal deoxynucleotidyl transferase dUTP nick-end labeling (TUNEL) assay with the use of the ApopTag Peroxidase in situ Apoptosis Detection kit (Chemicon, Temecula, CA).

\section{Flow Cytometric Analysis}

For analysis of early apoptosis, after treatment Caco-2 cells were harvested using TrypLE (Thermo-Fisher Scientific, Waltham, MA), resuspended in binding buffer, and stained with Annexin $\mathrm{V}$ and 7-aminoactinomycin D (7-AAD; BD Biosciences, San Jose, CA). With the assay for cellular reactive oxygen species (ROS), Caco-2 cells were treated with or without $20 \mu \mathrm{m}$ of acrolein for 24 hours. After washing, $10 \mu \mathrm{m}$ of cell permeant reagent 2',7'-dichlorofluorescein diacetate (DCFDA; SigmaAldrich) was added into wells and incubated at $37^{\circ} \mathrm{C}$ for 30 minutes. DCF fluorescence was monitored by fluorescence microscopy or flow cytometry. Flow cytometry was conducted using a FACSCanto II instrument, and data were analyzed with the use of CellQuest Pro software version 5.1 (BD Biosciences).

\section{Western Blot Analysis}

Equivalent amounts of protein from ileum or cell extracts were analyzed by standard Western blot techniques by using specific commercial antibodies. Proteins were visualized with the use of enhanced chemiluminescence (GE Healthcare, Piscataway, NJ) and quantified by densitometry using ImageJ software Java platform version 6 (NIH, Bethesda, MD). Blots were reprobed with antibody to $\beta$-actin to ensure equivalent loading. The density ratio of each band compared with its corresponding $\beta$-actin band was determined and normalized to the control value, which was set to 1 .

\section{RNA Isolation and Real-Time Quantitative PCR Analysis}

Total RNA was isolated by using TRIzol (Invitrogen) and subjected to real-time quantitative PCR with SYBR green I dye reagent and specific primers (designed using Primer-BLAST version 2.3.0; National Center for Biotechnology Information, $\mathrm{NIH}$ ) with an ABI prism 7500 system (Applied Biosystems, Foster City, CA). Dissociation curve analysis was performed to confirm primer specificity, and relative mRNA expression was calculated by using the $\Delta \Delta \mathrm{Ct}$ method from duplicate samples after normalization to $\beta$-actin.

\section{Histopathologic Analysis}

Ileum sections were stained with hematoxylin and eosin for histologic observation under an Olympus (Orangeburg, NY) BX41 light microscope. Five mice per group were analyzed, and 15 well-oriented villus-crypt junctions from 3 microscopy fields for each mouse were counted. Measurements of villi length and crypt depth from ileum of acrolein-treated or control mice were performed with the use of ImageJ. Ratios of villus height to crypt depth are presented. ${ }^{25}$

\section{Confocal Immunofluorescence Analysis}

Ileum sections were fixed in $10 \%$ buffered formalin for 24 hours and embedded in paraffin and subsequently were deparaffinized for immunodetection. Caco-2 cell monolayers were grown on culture slides, and after treatments cells were fixed and processed for immunodetection. Tissue sections or cell-slides were incubated with polyclonal rabbit antibodies specific for Claudin-1, Occludin, or ZO-1 (Invitrogen) overnight at $4^{\circ} \mathrm{C}$, followed by incubation of fluorescein isothiocyanate-conjugated antibody from Invitrogen for 30 minutes at room temperature. Images were examined on a Nikon (Melville, NY) A1R-A1 confocal microscope equipped with a digital image analysis system (Pixera, San Diego, CA).

\section{Statistical Analysis}

Statistical analysis was performed using GraphPad Prism version 5.01 for Windows (GraphPad Software, Inc., La Jolla, CA). Data were analyzed by unpaired analysis of variance with 


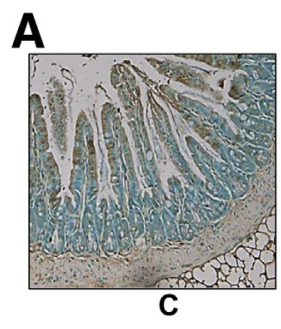

C

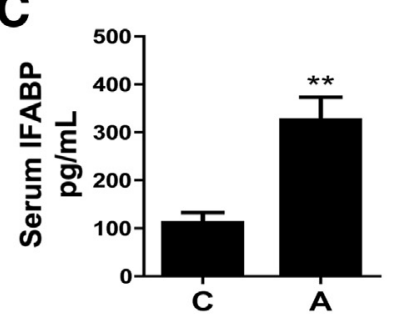

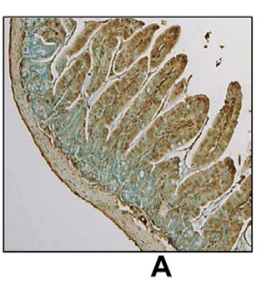

D
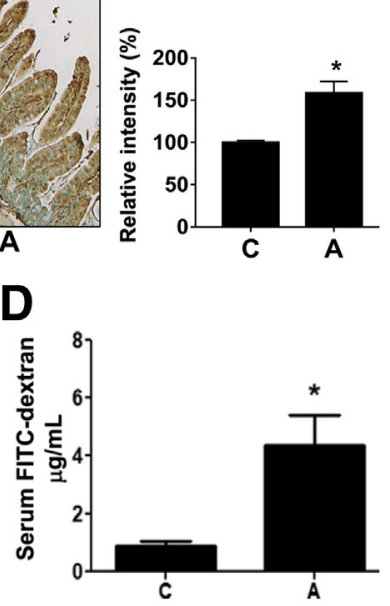

B

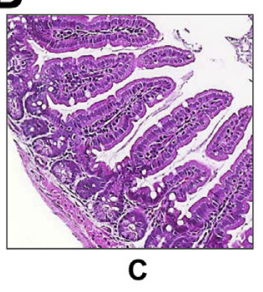

$\mathbf{E}$

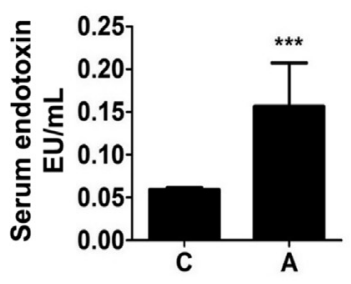

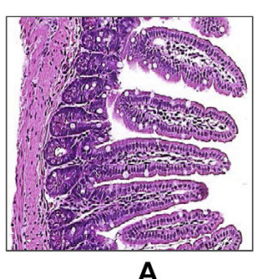

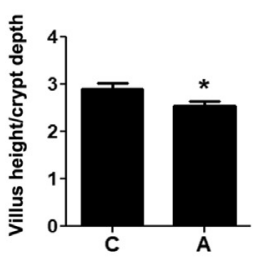

$\mathbf{F}$

Figure 1 Effect of oral acrolein gavage on acrolein-protein adduct accumulation, histopathologic findings, intestinal epithelial injury, and gut permeability in mice. Mice were exposed to acrolein by oral gavage $(5 \mathrm{mg} / \mathrm{kg}$, three times, separated by 12 hours). Serum and ileum samples were collected and processed as described in Materials and Methods. A: Accumulation of acrolein-protein adducts (seen as brown pigmentation) in the ileum of mice by immunohistochemistry using specific Ne-(3-formyl-3,4-dehydropiperidino) (FDP)-lysine antibodies. Graph shows the quantification of acrolein adducts using the MetaMorph Microscopy Automation and Image Analysis Software by calculating the percentage of positive (based on the average intensity of the field-ofview) microscope fields. B: Typical micrographs for ileum histologic examination with hematoxylin and eosin (H\&E) staining and observation under an Olympus BX41 light microscope. Measurements of villi length and crypt depth from ileum of acrolein-treated or control mice were performed with ImageJ software. Graph shows the ratios of villus height to crypt depth. C: Serum levels of intestinal fatty acid binding protein (IFABP; pg/mL). D: In vivo intestinal permeability assay measured serum levels of fluorescein isothiocyanate (FITC) - dextran (FD-4; $\mu \mathrm{g} / \mathrm{mL}$ ) 3 hours after FD- 4 oral administration. E: Serum levels of endotoxinlipopolysaccharide, endotoxin units per $\mathrm{mL}(\mathrm{EU} / \mathrm{mL})$. F: Correlation between serum levels of endotoxin and IFABP in mice by Pearson's correlation analysis. Data are expressed as means \pm SEM. $n=10$ images per ileum $(\mathbf{A}-\mathbf{E}) ; n=5$ mice $(\mathbf{A}$ and $\mathbf{B}) ; n=6$ mice $(\mathbf{C}-\mathbf{E}) .{ }^{*} P<0.05,{ }^{* *} P<0.01$, and ${ }^{* * *} P<0.001$ versus control (analysis of variance, Bonferroni test). Original magnification: $\times 20$ (A and $\mathbf{B})$. A, acrolein; $\mathbf{C}$, control.

Bonferroni posttest analysis. Differences were considered statistically significant for $P<0.05$.

\section{Results}

This study documented the effects of acrolein on intestinal epithelial barrier permeability, both in vitro and in vivo. The route of exposure was chosen as ingestion because high levels of acrolein exposure in humans are likely through food substances,${ }^{17}$ and dietary acrolein was highly likely to affect the intestinal barrier. Human exposure to acrolein by dietary consumption was estimated to be as much as $5 \mathrm{mg} /$ $\mathrm{kg}$; this level has demonstrated systemic effects in the liver and the cardiovascular system. ${ }^{17}$ In this study, the impact of this dose of acrolein on intestinal barrier function was examined after oral acrolein exposure to mice via oral gavage.

\section{Effects of Acrolein Exposure in Mice on Intestinal Accumulation of Acrolein Adducted Proteins and Ileum Morphologic Structure}

Initially it was to be determined whether oral acrolein was absorbed into the intestine. It was difficult to quantify free acrolein. However, acrolein reacted with cellular proteins to form adducts (eg, FDP-lysine) that could then be assessed. ${ }^{23}$ The formation of acrolein adducts after oral acrolein exposure was examined in the mouse ileum, because the ileum was particularly susceptible to injury after consumption of substances such as alcohol. ${ }^{3,26}$ Acrolein exposure increased the intestinal accumulation of acrolein-protein adducts (Figure 1A), with statistically significant differences on quantification. Adducts accumulation was seen primarily in the villi in epithelial cells and the lamina propria and in parts of the submucosa. Ileum morphologic structure (examined by histologic staining with hematoxylin and eosin) showed that acrolein exposure did not cause overt intestinal damage (Figure 1B). Further, to determine subtle changes in intestinal integrity by acrolein, 15 welloriented villus-crypt junctions for each ileum from 5 mice per group were measured. Although there was minimal change in the villi height, acrolein exposure resulted in an increase in crypt depth and, subsequently, a significant decrease in the ratio of villus height to crypt depth (Figure 1B); such changes have been shown to be associated with intestinal barrier dysfunction caused by alcohol consumption. $^{25}$

\section{Oral Acrolein Exposure in Mice Leads to Intestinal Epithelial Cell Damage, Increased Permeability, and Translocation of Bacterial Products}

To determine the functional consequence of oral acrolein exposure, the intestinal integrity and permeability in 

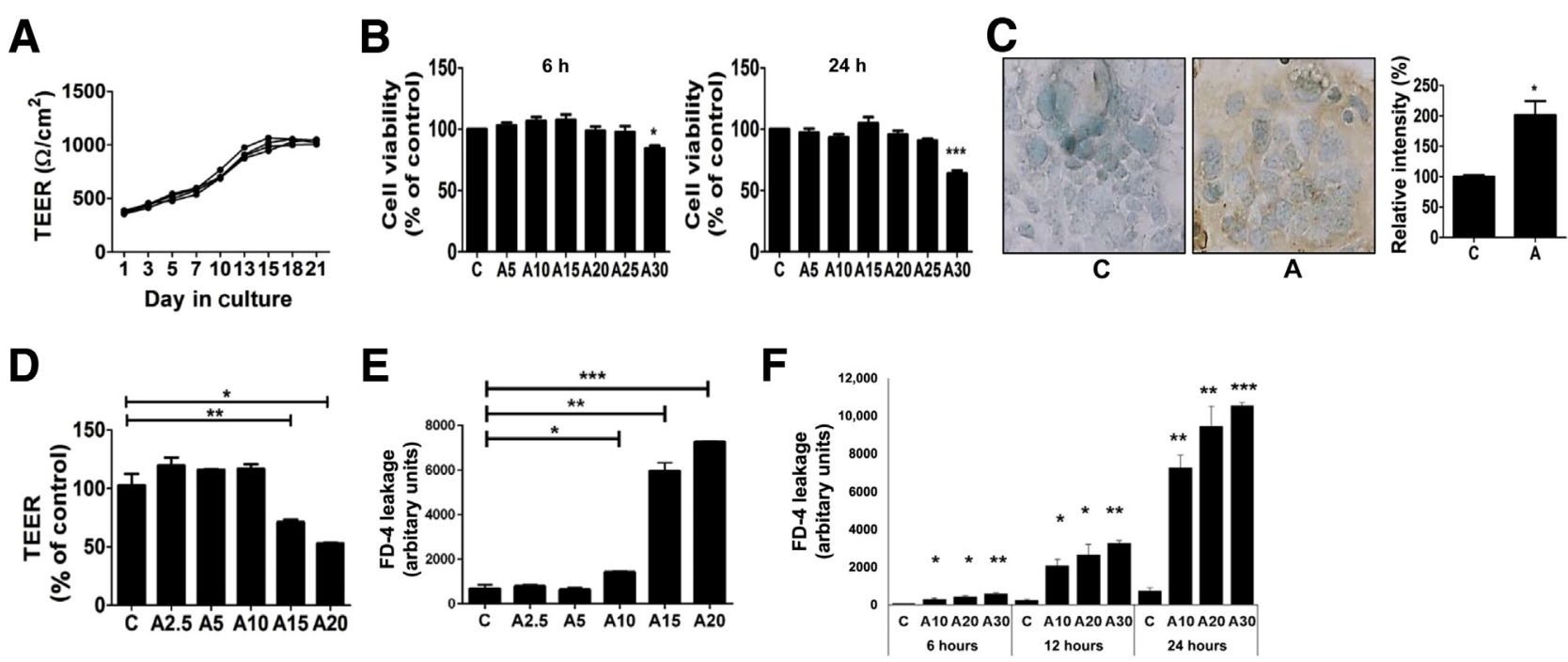

Figure 2 Acrolein exposure disrupts barrier function of Caco-2 cell monolayers and increases permeability. A: Time-dependent establishment of Caco-2 monolayer barrier was monitored from day 1 to day 21 and assayed by transepithelial electrical resistance (TEER) measurements. B: Effect of acrolein on Caco-2 cell viability. Caco-2 cells were treated with various concentrations of acrolein ( 5 to $30 \mu \mathrm{mol} / \mathrm{L}$ ) for 6 (left) and 24 (right) hours, and cell viability was determined by the MTT assay. C: Accumulation of acrolein-protein adducts by immunocytochemistry using specific Ne-(3-formyl-3,4-dehydropiperidino) (FDP)lysine antibodies and quantification of acrolein adducts in Caco-2 cells treated with $20 \mu \mathrm{mol} / \mathrm{L}$ acrolein for 24 hours. D: Effect of acrolein exposure (2.5 to 20 $\mu \mathrm{mol} / \mathrm{L}, 6$ hours) on TEER. E: Permeability of fluorescein isothiocyanate-dextran (FD-4) dye in response to acrolein (2.5 to $20 \mu \mathrm{mol} / \mathrm{L}, 24$ hours). F: Dose- (10, 20 , and $30 \mu \mathrm{mol} / \mathrm{L})$ and time- $(6,12$, and 24 hours) dependent effects of acrolein on barrier permeability to FD- 4 dye. Data are expressed as means \pm SEM. $n=10$ images per sample; $n=3(\mathbf{A}-\mathbf{F}) .{ }^{*} P<0.05,{ }^{*} P<0.01$, and ${ }^{* * *} P<0.001$ versus control at the corresponding time point (analysis of variance, Bonferroni test). Original magnification, $\times 40$. A, acrolein; $C$, control.

acrolein-fed mice were assessed. IFABP was exclusively expressed by enterocytes of the small bowel mucosa and was released into the circulation after enterocyte damage; it was an accepted marker for intestinal epithelial barrier damage. ${ }^{27-30}$ A significant approximately threefold increase in the serum levels of IFABP was seen in acrolein-fed mice (Figure 1C), indicating that epithelial cells are damaged/ ruptured by acrolein. This damage led to an increase in intestinal permeability which was measured directly by the in vivo intestinal FD-4 permeability assay. Serum levels of FD-4 were significantly elevated (3 hours after FD-4) in acrolein-fed mice compared with control mice (Figure 1D). Under normal circumstances with an intact intestinal barrier, only miniscule amounts of LPS entered into circulation from the intestinal lumen. Increased gut permeability caused more LPS to be translocated across the gut barrier; this increased serum/plasma LPS was a well-accepted marker of intestinal permeability and bacterial translocation. ${ }^{31,32}$ In parallel with the elevated IFABP, serum endotoxin concentration was measured and found to be significantly elevated (almost threefold) in the acrolein-fed animals (Figure 1E). Correlation analysis revealed that there was a strong positive correlation (Pearson's correlation coefficient, $r=0.625, P=0.013)$ between serum levels of IFABP and LPS (Figure 1F), indicating that acrolein-induced damage to the intestinal epithelium promoted barrier dysfunction leading to permeability and translocation of bacterial products.

To further investigate the mechanisms underlying acrolein-induced intestinal barrier dysfunction, the Caco-2 cell line was used as an additional model system (in vitro), along with the oral acrolein exposure in mice (in vivo). Caco-2 monolayers represented a reliable and well-accepted model that simulated the intestinal epithelial barrier for barrier function and permeability studies. ${ }^{22,33,34}$

\section{Acrolein Exposure Impairs Intestinal Barrier Function of Caco-2 Cell Monolayers}

Initially, the establishment and barrier integrity of the Caco2 monolayers grown in culture was confirmed (Figure 2A). TEER increased significantly starting from day 7 after seeding and continued to rise until day 18 , when it stabilized above $1000 \Omega / \mathrm{cm}^{2}$. All subsequent experiments were conducted on established Caco-2 monolayers (TEER of $>1000$ $\Omega / \mathrm{cm}^{2}$ ). The effects of increasing concentrations of acrolein were examined on the viability of Caco-2 by using the MTT assay. From the cytotoxicity of acrolein in other cells, ${ }^{13}-2$ cell monolayers were exposed to varying concentrations of acrolein ( 5 to $30 \mu \mathrm{mol} / \mathrm{L}$ ) for 6 and 24 hours and measured cell survival. Minimal loss of survival was observed from $5 \mu \mathrm{mol} / \mathrm{L}$ through $25 \mu \mathrm{mol} / \mathrm{L}$ at both time points, and a significant $(>40 \%)$ cell death was seen at $30 \mu \mathrm{mol} / \mathrm{L}$ at 24 hours (Figure 2B), showing that higher concentrations of acrolein are cytotoxic. Further, similar to the in vivo data, increased accumulation of acrolein-adducted proteins was seen in Caco-2 cells exposed for 24 hours to acrolein at a noncytotoxic concentration $(20 \mu \mathrm{mol} / \mathrm{L})$, with statistically significant differences on quantification, compared with control cells (Figure 2C). 


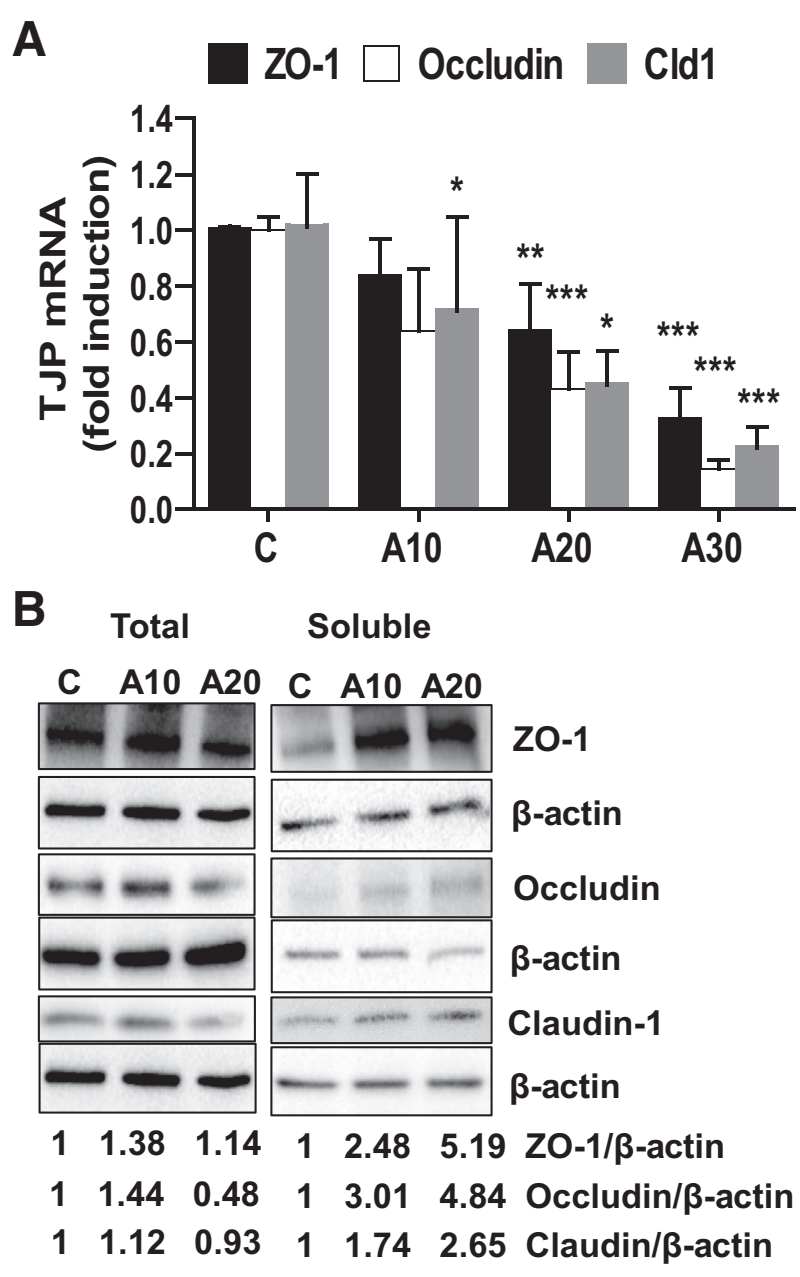

Figure 3 Acrolein exposure leads to down-regulation and redistribution of tight junction protein (TJP) in Caco-2 cells. A: Zonula occludens (ZO)-1 (black), Occludin (white), and Claudin-1 (Cld1; gray) mRNA levels at 24 hours in Caco-2 cells, with or without acrolein exposure (10, 20, and 30 $\mu \mathrm{mol} / \mathrm{L}$ ). B: Total and soluble (nonmembrane associated) protein levels of Z0-1, Occludin, and Claudin-1 in untreated or acrolein-treated Caco-2 cells at 24 hours by Western blot analysis. Blots were reprobed with antibody to $\beta$-actin to ensure equivalent loading. Numbers represent mean densitometry ratios; the density ratio of each band compared with its corresponding $\beta$-actin band was determined and normalized to the control value, which was set to 1 . Data are expressed as means \pm SEM. $n=3$. ${ }^{*} P<0.05$, ${ }^{* *} P<0.01$, and ${ }^{* * *} P<0.001$ versus control (analysis of variance, Bonferroni test). A, acrolein; C, control (A10, A20, A30 $\mu \mathrm{mol} / \mathrm{L})$.

Then the impact of acrolein on barrier integrity and permeability were examined in vitro. Epithelial barrier integrity was measured by using the TEER assay, ${ }^{35}$ and paracellular barrier permeability was assessed by the FD-4 leakage assay. ${ }^{22}$ Acrolein exposure of Caco-2 monolayers at low, noncytotoxic concentrations resulted in a doserelated decrease in TEER, with no effects at 2.5 or 5 $\mu \mathrm{mol} / \mathrm{L}$, a slight downward trend at $10 \mu \mathrm{mol} / \mathrm{L}$, and a statistically significant decrease at 15 and $20 \mu \mathrm{mol} / \mathrm{L}$ (Figure 2D). Consistent with these results, the paracellular permeability of FD-4 was significantly increased by acrolein, starting from $10 \mu \mathrm{mol} / \mathrm{L}$ (Figure $2 \mathrm{E}$ ), showing that low, noncytotoxic levels of acrolein caused barrier permeability.
Further, permeability of FD-4 dye was found to increase significantly over time from 6 to 24 hours at both noncytotoxic $(10$ and $20 \mu \mathrm{mol} / \mathrm{L})$ and cytotoxic $(30 \mu \mathrm{mol} / \mathrm{L})$ acrolein concentrations (Figure 2F). These data suggested that the changes in epithelial barrier function and permeability at lower noncytotoxic levels were independent of acrolein cytotoxicity and that mechanisms other than cell death may be involved.

\section{Acrolein Exposure Leads to Down-Regulation and Cellular Redistribution of TJP}

Because increased permeability caused by acrolein may result from disruption of the tight junctions that critically regulated paracellular permeability and barrier function, we examined the expression (mRNA and protein levels) of three key TJPs (ZO-1, Claudin-1, and Occludin), which are disturbed/affected by factors such as alcohol and inflammatory cytokines/chemokines. ${ }^{36-38}$ Our data demonstrated that acrolein significantly down-regulated mRNA levels of ZO-1, Occludin, and Claudin-1 in Caco-2 cells (Figure 3A). The total TJP protein levels showed variable changes in response to acrolein; all three proteins were slightly elevated at $10 \mu \mathrm{mol} / \mathrm{L}$ acrolein. At $20 \mu \mathrm{mol} / \mathrm{L}$ acrolein, Occludin was markedly down-regulated to $<50 \%$, and Claudin- 1 was slightly reduced. However, ZO-1 was slightly increased at both concentrations (Figure 3B). In addition to total protein levels, the cellular location and membrane association were critical for TJP function, and any alterations in localization could greatly affect barrier permeability; hence, the localization of TJPs was also determined. Therefore, the partitioning and relative levels of TJPs were examined in the membrane-associated and the nonmembrane associated (soluble) protein fractions by Western blot analysis. Acrolein treatment resulted in a dramatic increase in the soluble levels of all three TJPs, indicating that their membrane association was significantly disrupted by acrolein (Figure 3B). No changes were seen in the membrane-bound levels (not shown).

To further support these findings, ZO-1, Claudin-1, and Occludin were examined by immunofluorescence staining to assess TJP localization in whole cells rather than extracted proteins. In untreated cells, a continuous regular pattern of ZO-1 was seen at the cell borders surrounding the plasma membrane that constituted the cell-cell junctions between adjacent epithelial cells (Figure 4A). In contrast, compared with the continuous and organized pattern in untreated cells, acrolein-treated cells displayed an uneven (ruffled) distribution, which was decreased/discontinuous at some locations, with random clumping at others (Figure 4A). A similar pattern was seen examining Occludin, with occludin primarily at the plasma membrane in control cells. On acrolein exposure, the protein was displaced from the plasma membrane and was diffused throughout the cytoplasm (Figure 4A). Unlike the defined distribution of ZO-1 and Occludin, Claudin-1 exhibited a 
A
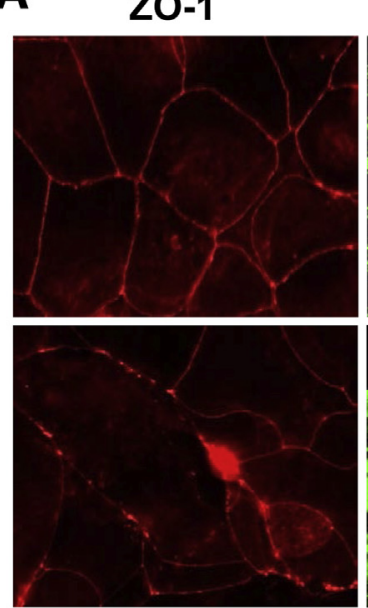

B
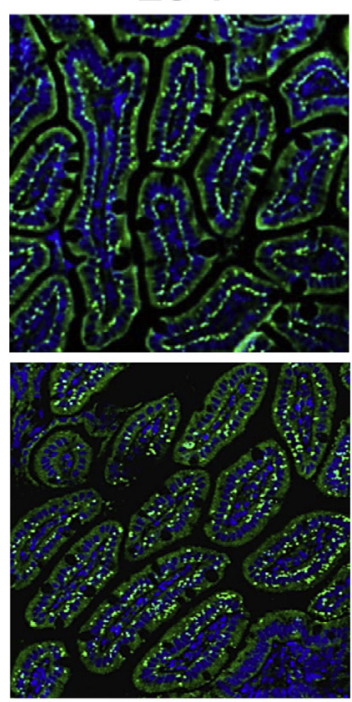

Occludin
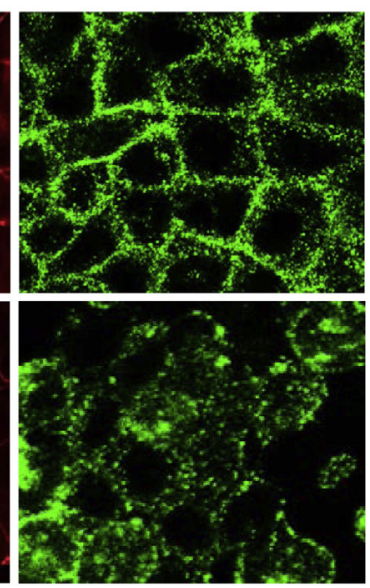

Occludin
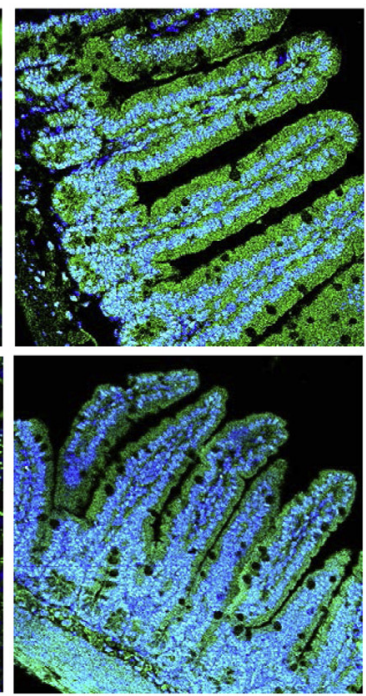

Claudin-1

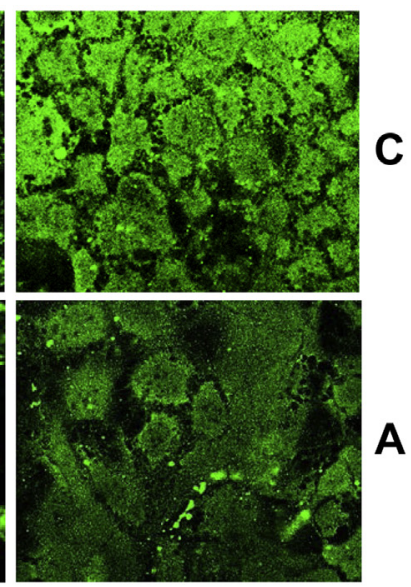

A
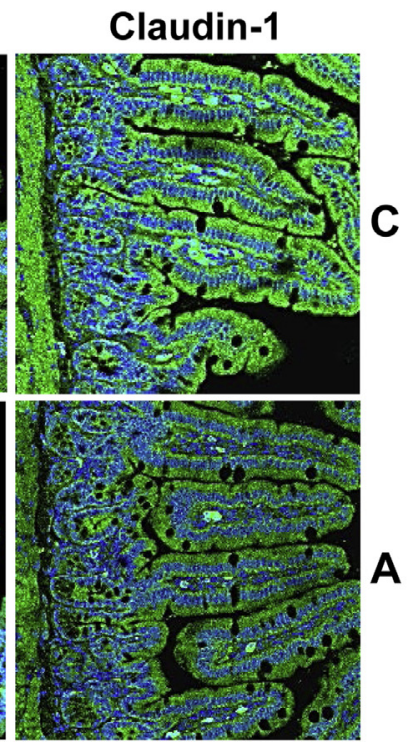

Figure 4 Localization of zonula occludens (Z0)-1, Occludin, and Claudin-1 after acrolein exposure in vitro and in vivo. A: Immunofluorescence staining of Z0-1 (left column), Occludin (middle column), and Claudin-1 (right column) in Caco-2 cells. B: Z0-1, Occludin, and Claudin-1 visualized by immunofluorescence staining in sections of mouse ileum. Green indicates Z0-1 (left column), Occludin (middle column), or Claudin-1 (right column); blue, DAPI counterstaining of the nuclei. Images were examined with a Nikon A1R-A1 confocal microscope equipped with a digital image analysis system (Pixera, San Diego, CA). $n \geq 3$ images per tissue section and 5 mice per experimental group. Original magnification, $\times 40$. A, acrolein; C, control $(20 \mu \mathrm{mol} / \mathrm{L})$. diffuse pattern throughout the cell, and the overall fluorescence intensity of Claudin-1 was reduced in the acroleintreated cells, suggesting a decrease in total Claudin-1 protein (Figure 4A).

The effects of oral acrolein exposure was also examined on intestinal TJPs in the ileum of mice. Unlike Caco- 2 cells, TJP mRNA and protein levels did not differ significantly in the ileum of acrolein-fed animals (not shown). The distribution and localization of ZO-1, Occludin, and Claudin-1 in mice ileum were examined by confocal microscopy. ZO-1 exhibited a punctate pattern that was ordered and uniform in control mice; in contrast, the acrolein-fed animals showed disorganized and random ZO-1 staining (Figure 4B).

In control mice, Occludin and Claudin-1 were located primarily at the superficial layer of the ileal mucosa consistent with epithelial TJP distribution. In the acrolein group, the staining patterns were largely similar, except for a slight thinning and discontinuity of the epithelial border. Notably, the staining intensity in acrolein-fed mice was significantly lower for both proteins compared with the control group, suggesting that the overall levels of Occludin and Claudin-1 may be decreased (Figure 4B). These data showed that acrolein exposure, both in vitro and in vivo, led to either down-regulation and/or redistribution of ZO-1, Claudin-1, and Occludin, thereby enhancing permeability.

\section{Effects of Acrolein Exposure on Intestinal Epithelial Cell Death}

Our in vitro data showed that acrolein exposure had dosedependent effects on cell viability, with significant cytotoxicity at $30 \mu \mathrm{mol} / \mathrm{L}$ concentration (Figure 2B). Epithelial cell death was known to be a significant mechanism that contributed to intestinal barrier dysfunction/permeability, and increased apoptosis has been reported in animals and humans in association with increased intestinal permeability and disease pathogenesis. $^{7-9,39}$ Accordingly, the in vivo effect of oral acrolein exposure on epithelial cell death was 
A
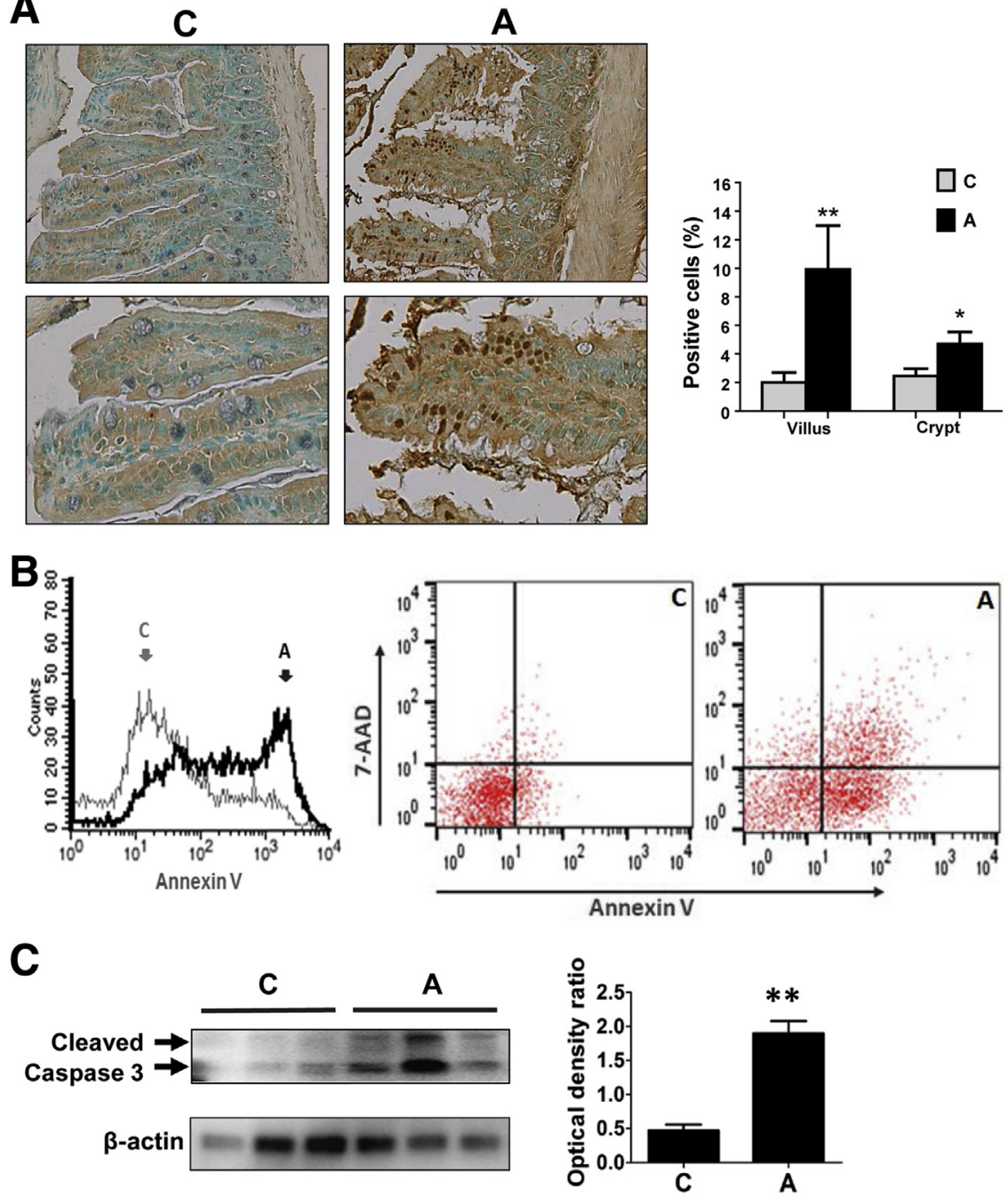

Figure 5 Acrolein exposure causes intestinal epithelial cell apoptosis. A: Cell apoptosis in ileum of mice by deoxynucleotidyl transferase dUTP nickend labeling (TUNEL) staining. Graph shows quantification of apoptosis by counting TUNELpositive cells in crypts and villi with ImageJ. B: Flow cytometric analysis of acrolein-induced early apoptosis in Caco-2 cells stained with Annexin V and 7-aminoactinomycin D (7-AAD). Histogram of Annexin $\mathrm{V}$ fluorescence intensity in untreated control or acrolein-exposed cells (left panel). Dot plots denoting single-positive and double-positive cells in control group (middle panel) or acrolein treatment group (right panel). C: Detection of activated caspase- 3 by Western blot analysis in the ileum of acrolein-exposed or control mice. Blots were stripped and reprobed with a $\beta$-actin antibody as loading control. Graph represents the density ratios of each band compared with its corresponding $\beta$-actin. Data are expressed as means \pm SEM. $n=15$ microscopy fields and 5 mice per group (A); $n=3$ (C). ${ }^{*} P<0.05$ and ${ }^{*} P<0.01$ versus control by analysis of variance, Bonferroni test. Original magnification: $\times 20$ (A, top row); $\times 40$ (A, bottom row). A, acrolein; C, control. examined in mice. Acrolein exposure resulted in an increase in TUNEL-positive cells in the ileum of acrolein-fed mice compared with controls; cell death was predominantly seen in the villi and was less prevalent in the crypt regions. Quantification showed that TUNEL-positive cells were increased by acrolein by approximately fivefold in the villi and twofold in the crypts (Figure 5A). Further, acroleinexposed Caco-2 cells were analyzed by flow cytometry using Annexin V (marker of early apoptosis) and 7-AAD (marker of cell death/necrosis). Acrolein exposure caused a major shift in the Annexin $\mathrm{V}$ fluorescence intensity (Figure 5B). Double staining with Annexin V and 7-AAD showed that, compared with untreated control cells, acrolein exposure increased the population of cells undergoing early apoptosis (Annexin V positive and 7-AAD negative) from $5.8 \%$ to $52.9 \%$. An increase (from $1.6 \%$ to $15.5 \%$ ) was also seen in the double-positive population (Annexin $\mathrm{V}$ positive and 7-AAD positive) that may represent cells undergoing late-stage apoptosis or necroptosis (Figure 5B). In addition, the proteolytic activation of caspase-3, a hallmark of cells undergoing apoptosis, was assessed by Western blot analysis. Oral acrolein exposure led to caspase 3 activation as seen by the twofold increase in cleaved caspase 3 in mice ileum (Figure 5C), suggesting that acrolein caused apoptotic cell death in intestinal epithelial cells.

To further characterize acrolein-induced cell death, oxidative stress and ER stress were assessed, both of which are known to be caused by acrolein exposure and can, in turn, cause cell death. ${ }^{24}$ Accordingly, oxidative stress in Caco-2 cells was measured by using the cell-permeant dye, DCFDA, which has commonly been used as an indicator for ROS. The nonfluorescent DCFDA underwent oxidation by ROS and was converted into the highly fluorescent DCF. Acrolein exposure induced a significant increase in ROS generation in Caco-2 cells, reflected by increased DCF fluorescence as measured by immunofluorescence microscopy and flow cytometry (Figure 6A).

Recent evidence suggested that ER stress was a main feature in intestinal cell dysfunction and death, both of which contributed to inflammation and disease 

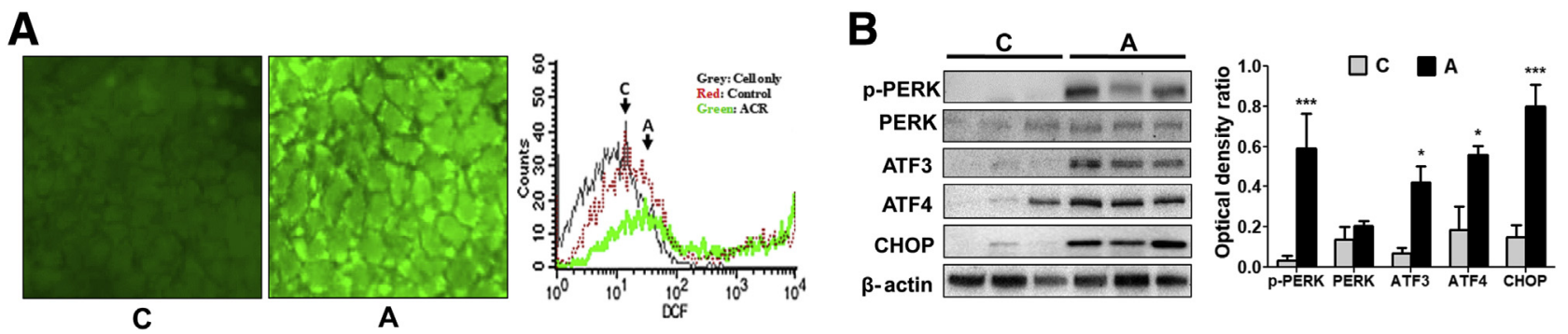

Figure 6 Acrolein exposure causes intestinal oxidative stress and endoplasmic reticulum (ER) stress. A: $2^{\prime}, 7^{\prime}$-Dichlorofluorescein (DCF) fluorescence in Caco-2 cells incubated with DCF diacetate (DCFDA). Representative microscopy images of control (left panel) and acrolein-exposed (middle panel) Caco-2 cells. Flow cytometric analysis showing DCF fluorescence intensity (right panel) of control and acrolein-exposed Caco-2 cells. B: Expression of ER stressrelated proteins phospho protein kinase RNA-like endoplasmic reticulum kinase (p-PERK), ATF3, ATF4, and CCAAT/enhancer-binding protein homologous protein (CHOP) in the ileum of control and oral acrolein-exposed mice by Western blot analysis. Blots were reprobed with antibody to $\beta$-actin to ensure equivalent loading. Graph represents the optical density ratios of each band compared with its corresponding $\beta$-actin band. Data are expressed as means \pm SEM. $n=3(B) .{ }^{*} P<0.05$ and ${ }^{*} * *<0.001$ versus control (analysis of variance, Bonferroni test). Original magnification, $\times 20$. A, acrolein; ACR, acrolein; C, control (20 $\mathrm{mol} / \mathrm{L})$.

pathogenesis. ${ }^{40-42}$ Moreover, studies by us and others have shown that acrolein could trigger ER stress, leading to acrolein-induced apoptosis in several cell types, including hepatocytes ${ }^{24}$ human A549 lung cells,${ }^{43}$ and mouse lung epithelial cells, ${ }^{44}$ as well as in vivo in mice lungs. ${ }^{45}$ In this study, the activation of ER stress was examined in the ileum of acrolein-fed mice. The activation/expression (protein levels) of a panel of hallmark genes known to be involved in the ER stress response was measured by Western blot analysis (Figure 6B). Acrolein gavage resulted in the activation by phosphorylation of the upstream signaling protein PERK, which was the key initiator of one of three major ER stress signaling cascades. Acrolein-induced phospho-activation of PERK resulted in the subsequent up-regulation of the ER stress-associated transcription factors, ATF3 and ATF4, by sixfold and fourfold, respectively. A key target of the transcription factor ATF4 was the proapoptotic protein CHOP (also called DDIT or GADD 153), which activated death pathways leading to ER-dependent cell apoptosis. ${ }^{4,47}$ Exposure to oral acrolein caused a significant up-regulation (more than fivefold) of CHOP compared with control mice (Figure 6B). The data showed that acrolein exposure resulted in increased oxidative stress and ER stressmediated CHOP up-regulation, leading to intestinal epithelial cell apoptosis.

\section{Discussion}

Experimental and clinical evidence shows that damaged intestinal epithelial integrity and barrier dysfunction are the two fundamental causes of increased intestinal permeability and translocation of bacteria/bacterial products. Environmental and dietary factors are known to influence gut permeability, and epidemiologic studies reveal an association between these factors and intestinal diseases such as IBD, appendicitis, and irritable bowel syndrome. This study examined the intestinal impact of acrolein, which is an environmental/ dietary pollutant and an endogenous cellular metabolite.
Our results demonstrate that oral acrolein exposure causes loss of integrity of the intestinal epithelium, leading to impaired barrier function and gut permeability both in vitro and in vivo. Our data define critical mechanistic interactions between the intestine and dietary factors and show that foods rich in acrolein (or oxidized fats) could disrupt intestinal barrier function and enhance gut permeability. Indeed, the consumption of diets high in fat (good substrate for acrolein generation) is known to affect intestinal barrier function and to enhance IBD. ${ }^{48,49}$ Because diet can also cause major pathogenic alterations in gut microbiota that lead to dysbiosis, it will be interesting to determine whether acrolein also alters the intestinal microbial composition and changes the ratios of beneficial and pathogenic microorganisms. Several proteins, such as Occludin, Claudins, and ZOs, help maintain the structure/integrity of intestinal tight

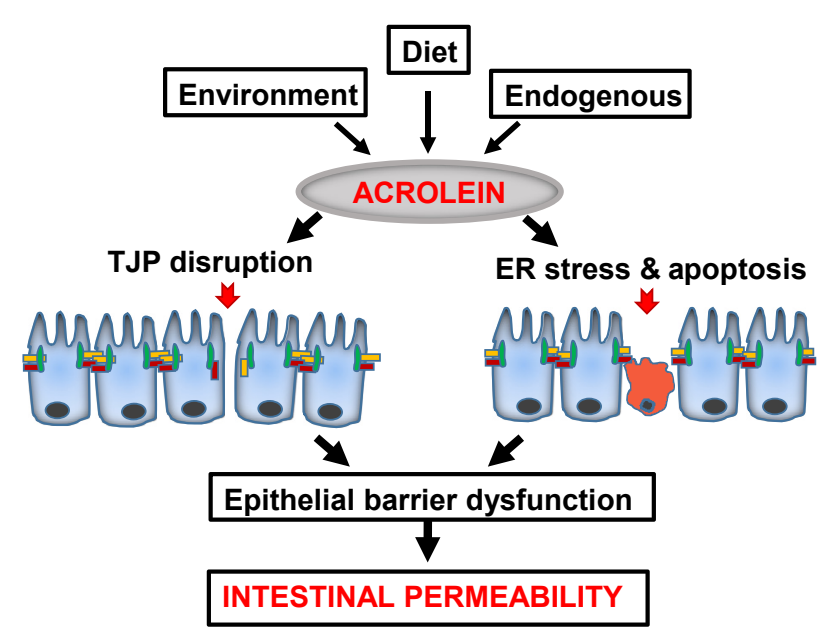

Figure 7 Schematic shows that acrolein impairs intestinal epithelial barrier function and causes permeability. Acrolein exposures may be exogenous through diet or environment or endogenous by cellular metabolism and lipid peroxidation. Intestinal barrier dysfunction caused by acrolein may be more subtle by alterations of tight junction proteins (TJPs) or more profound by epithelial cell death. ER, endoplasmic reticulum. 
junctions. Previous studies have indicated that alterations in ZO-1 and Claudin-1 are associated with increased intestinal permeability and a higher susceptibility to alcoholic liver disease $^{3,26,50}$ and intestinal ischemia-reperfusion injury. ${ }^{51}$ Similarly, our study shows that acrolein exposure resulted in down-regulation and/or redistribution of ZO-1, Claudin1 , and Occludin, suggesting that these TJPs are critical in acrolein-induced gut barrier dysfunction. Further, our study demonstrates the importance of the level and appropriate localization of these TJPs in maintaining epithelial barrier integrity. Both epithelial and endothelial barriers are maintained by tight monolayers of polarized cells that form a defensive barricade against toxicants and pathophysiological insults. Inhaled acrolein is known to impair lung epithelial barrier function and to induce epithelial cell death that leads to lung injury. ${ }^{52}$ Our findings emphasize the possibility that acrolein may have toxic effects on the epithelial and endothelial barriers in many organ systems that maintain selective permeability. Relevant to this, increased acrolein levels are associated with certain neurologic diseases such as Parkinson and Alzheimer. ${ }^{53,54}$

Several mechanisms that cause dysregulation of TJPs have been described in the literature. ${ }^{55,56}$ Myosin light chain kinase (MLCK) is a key regulator of intestinal tight junction dysfunction in inflammatory conditions, particularly in response to cytokines such as tumor necrosis factor- $\alpha$. The regulation of MLCK is complex and involves activation of upstream mitogen-activated protein kinases, transcriptional and post-translational alterations of MLCK, and various splice variants (short and long). Our data demonstrate that acrolein exposure results in the buildup of acrolein adducts concomitant with TJP disruption and increased barrier permeability in cultured cells and mice. It is known that acrolein adduction of proteins leads to changes in their posttranslational modifications and alteration of function. ${ }^{13}$ The intestinal effects of acrolein may be direct, by adduction with TJPs, thereby changing their structure/function/localization, or the effects may be indirect. Both cytoplasmic and nuclear acrolein adduct accumulation was seen; adduction of nuclear proteins (eg, transcription factors and chromatin modifiers) can elicit major alterations in the expression of TJPs and other genes. The detailed mechanisms by which acrolein causes alterations in TJPs and barrier dysfunction are currently under investigation in our laboratory.

The paracellular pathway involving TJPs, even when disrupted, is not capable of transporting large molecules and bacteria. For translocation of bacteria, other routes must be invoked such as epithelial gaps created by dying/apoptotic enterocytes. Indeed, our study shows that acrolein not only causes TJP disruption but also activates epithelial cell death in cultured cells and mice. Acrolein exposure increased cellular ROS, which is known to contribute to cell death. In addition, acrolein exposure up-regulated ER stressassociated proteins ATF3, ATF4 and pro-apoptotic CHOP, leading to apoptosis in the intestinal epithelial cells. Further, the robust positive correlation between serum IFABP and endotoxin strongly suggests that epithelial cell damage may be a causal factor in acrolein-induced intestinal permeability. Acrolein-induced cell death appeared to be primarily apoptotic as seen by caspase-3 cleavage and Annexin V flow cytometry; however, other forms of cell death such as necroptosis and necrosis may occur concurrently. Indeed, we have shown previously in hepatic cells that acrolein induces both apoptosis and necrosis in a time- and dosedependent manner. ${ }^{24}$ Our data demonstrate that apoptotic death of intestinal epithelial cells is a predominant feature of dietary acrolein-induced intestinal barrier dysfunction and resultant permeability. Thus, increased acrolein exposures may alter the steady-state intestinal epithelial homeostasis and may allow translocation of both bacterial products/ toxins and even bacteria, leading to consequent systemic inflammation and tissue injury.

From our findings, the prevention of excessive intestinal acrolein exposure and consequent gut permeability may be of clinical importance. Acrolein scavengers have been used to attenuate acrolein-induced injury in other cell types and organs. ${ }^{57,58}$ Scavengers such as hydralazine and phenelzine, and antioxidants (eg, N-acetyl cysteine and 2-mercaptoethane sulfonate $\mathrm{Na}$ ), which have shown protection against acrolein cytotoxicity, are potential candidates to be tested. From our finding that ER stress-mediated apoptosis is an underlying mechanism of acrolein-induced barrier dysfunction, it will be interesting to test the protective effects of inhibitors of ER stress, such as 4-phenylbutyrate that is known to prevent acrolein cytotoxicity in hepatocytes. ${ }^{24}$ Further studies to investigate therapeutic strategies that prevent or protect against acroleininduced intestinal dysfunction and injury are needed.

It is difficult to correlate in vitro acrolein concentrations with in vivo oral exposure. The amount of acrolein in food that can be absorbed in vivo does not necessarily correspond to the concentrations of exposure that affect cells in culture. Published estimates suggest that daily consumption of unsaturated aldehydes is nearly $5 \mathrm{mg} / \mathrm{kg}^{17}$; hence, we used this acrolein dose in mice. Acrolein concentrations used in vitro on other cell types range from 0.5 to $200 \mu \mathrm{mol} / \mathrm{L} .{ }^{13}$ In this study, we chose to test the effects of both cytotoxic and noncytotoxic doses of acrolein in vitro. Our data suggest that acrolein has dose-dependent effects on the intestine and that acrolein levels control the magnitude and mechanisms of gut barrier dysfunction. Note that acrolein is also generated endogenously by cellular metabolism of polyamines and amino acids and by lipid peroxidation, all of which are enhanced with high-fat diet, obesity, alcohol abuse, or cigarette smoking. ${ }^{54,59-61}$ The endogenous generation of acrolein may synergize with exogenous acrolein exposures from environmental or dietary sources to further increase intestinal permeability.

This study provides novel insights into the intestinal effects of acrolein. However, the results obtained from this study of oral acrolein exposure in mice may not directly translate to humans. Moreover, the toxic effects of acrolein may depend largely on how rapidly and extensively it is metabolized, based on the metabolic capacity and enzyme systems. Thus, human 
susceptibility to acrolein-induced intestinal barrier dysfunction may be different from mice, but the underlying mechanisms may be similar. In addition, factors such as age, sex, and genetic polymorphisms may be relevant co-modifiers. Further epidemiologic, clinical, and experimental studies are needed to adequately address these issues.

\section{Conclusions}

We have identified that acrolein has an impact on the intestinal epithelial barrier that involves decrease/redistribution and discontinuous localization of TJPs and epithelial cell apoptosis, resulting in loss of integrity of the epithelial cell monolayer and permeability (Figure 7). Our findings highlight the consequences of acrolein consumption/exposure on the intestinal microenvironment. Overall, our results indicate that exposure to acrolein contributes to intestinal barrier dysfunction and gut permeability and consequent systemic bacterial translocation, thereby leading to enhanced inflammation, injury, and susceptibility to disease.

\section{Acknowledgments}

We thank Dr. David Barker for designing and testing realtime quantitative PCR primers and Marion McClain for editing the manuscript.

W.-Y.C. conducted experiments, acquired, analyzed, and interpreted data, and prepared figures; M.W. conducted experiments and acquired, analyzed, and interpreted data; J.Z. conducted experiments and provided technical support; S.S.B. conceived and designed the study and critically revised the manuscript; C.J.M. conceived the study, critically revised the manuscript and provided funding; S.J.-B. conceived the research and designed the study, acquired, analyzed, and interpreted the data, drafted and critically revised the manuscript, and provided funding.

\section{References}

1. Bischoff SC, Barbara G, Buurman W, Ockhuizen T, Schulzke JD, Serino M, Tilg H, Watson A, Wells JM: Intestinal permeability-a new target for disease prevention and therapy. BMC Gastroenterol 2014, 14:189

2. Michielan A, D'Inca R: Intestinal permeability in inflammatory bowel disease: pathogenesis, clinical evaluation, and therapy of leaky gut. Mediators Inflamm 2015, 2015:628157

3. Szabo G: Gut-liver axis in alcoholic liver disease. Gastroenterology 2015, 148:30-36

4. Odenwald MA, Turner JR: The intestinal epithelial barrier: a therapeutic target? Nat Rev Gastroenterol Hepatol 2017, 14:9-21

5. Lee SH: Intestinal permeability regulation by tight junction: implication on inflammatory bowel diseases. Intest Res 2015, 13:11-18

6. Gunther C, Neumann H, Neurath MF, Becker C: Apoptosis, necrosis and necroptosis: cell death regulation in the intestinal epithelium. Gut 2013, 62:1062-1071

7. Hagiwara C, Tanaka M, Kudo H: Increase in colorectal epithelial apoptotic cells in patients with ulcerative colitis ultimately requiring surgery. J Gastroenterol Hepatol 2002, 17:758-764
8. Zeissig S, Bojarski C, Buergel N, Mankertz J, Zeitz M, Fromm M, Schulzke JD: Downregulation of epithelial apoptosis and barrier repair in active Crohn's disease by tumour necrosis factor alpha antibody treatment. Gut 2004, 53:1295-1302

9. Di Sabatino A, Ciccocioppo R, Luinetti O, Ricevuti L, Morera R, Cifone MG, Solcia E, Corazza GR: Increased enterocyte apoptosis in inflamed areas of Crohn's disease. Dis Colon Rectum 2003, 46: $1498-1507$

10. Martin TD, Chan SS, Hart AR: Environmental factors in the relapse and recurrence of inflammatory bowel disease: a review of the literature. Dig Dis Sci 2015, 60:1396-1405

11. Calkins BM: A meta-analysis of the role of smoking in inflammatory bowel disease. Dig Dis Sci 1989, 34:1841-1854

12. Cosnes J, Beaugerie L, Carbonnel F, Gendre JP: Smoking cessation and the course of Crohn's disease: an intervention study. Gastroenterology 2001, 120:1093-1099

13. Moghe A, Ghare S, Lamoreau B, Mohammad M, Barve S, McClain C, Joshi-Barve S: Molecular mechanisms of acrolein toxicity: relevance to human disease. Toxicol Sci 2015, 143:242-255

14. Abraham K, Andres S, Palavinskas R, Berg K, Appel KE, Lampen A: Toxicology and risk assessment of acrolein in food. Mol Nutr Food Res 2011, 55:1277-1290

15. Fullana A, Carbonell-Barrachina AA, Sidhu S: Comparison of volatile aldehydes present in the cooking fumes of extra virgin olive olive, and canola oils. J Agric Food Chem 2004, 52:5207-5214

16. Watzek N, Scherbl D, Feld J, Berger F, Doroshyenko O, Fuhr U, Tomalik-Scharte D, Baum M, Eisenbrand G, Richling E: Profiling of mercapturic acids of acrolein and acrylamide in human urine after consumption of potato crisps. Mol Nutr Food Res 2012, 56: $1825-1837$

17. Wang GW, Guo Y, Vondriska TM, Zhang J, Zhang S, Tsai LL, Zong NC, Bolli R, Bhatnagar A, Prabhu SD: Acrolein consumption exacerbates myocardial ischemic injury and blocks nitric oxideinduced PKCepsilon signaling and cardioprotection. J Mol Cell Cardiol 2008, 44:1016-1022

18. Ismahil MA, Hamid T, Haberzettl P, Gu Y, Chandrasekar B, Srivastava S, Bhatnagar A, Prabhu SD: Chronic oral exposure to the aldehyde pollutant acrolein induces dilated cardiomyopathy. Am J Physiol Heart Circ Physiol 2011, 301:H2050-H2060

19. Conklin DJ, Prough RA, Juvan P, Rezen T, Rozman D, Haberzettl P, Srivastava S, Bhatnagar A: Acrolein-induced dyslipidemia and acutephase response are independent of HMG-CoA reductase. Mol Nutr Food Res 2011, 55:1411-1422

20. Romero A, Ares I, Ramos E, Castellano V, Martinez M, MartinezLarranaga MR, Anadon A, Martinez MA: Mycotoxins modify the barrier function of Caco-2 cells through differential gene expression of specific claudin isoforms: protective effect of illite mineral clay. Toxicology 2016, 353-354:21-33

21. Tanaka-Okamoto $\mathrm{M}$, Hori $\mathrm{K}$, Ishizaki $\mathrm{H}$, Itoh $\mathrm{Y}$, Onishi $\mathrm{S}$, Yonemura S, Takai Y, Miyoshi J: Involvement of afadin in barrier function and homeostasis of mouse intestinal epithelia. J Cell Sci $2011,124: 2231-2240$

22. Zhao H, Zhao C, Dong Y, Zhang M, Wang Y, Li F, Li X, McClain C, Yang S, Feng W: Inhibition of miR122a by Lactobacillus rhamnosus GG culture supernatant increases intestinal occludin expression and protects mice from alcoholic liver disease. Toxicol Lett 2015, 234: 194-200

23. Chen W-Y, Zhang J, Ghare S, Barve S, McClain C, Joshi-Barve S: Acrolein is a pathogenic mediator of alcoholic liver disease and the scavenger hydralazine is protective in mice. Cell Mol Gastroenterol Hepatol 2016, 2:685-700

24. Mohammad MK, Avila D, Zhang J, Barve S, Arteel G, McClain C, Joshi-Barve S: Acrolein cytotoxicity in hepatocytes involves endoplasmic reticulum stress, mitochondrial dysfunction and oxidative stress. Toxicol Appl Pharmacol 2012, 265:73-82

25. Chen RC, Xu LM, Du SJ, Huang SS, Wu H, Dong JJ, Huang JR, Wang XD, Feng WK, Chen YP: Lactobacillus rhamnosus GG 
supernatant promotes intestinal barrier function, balances Treg and TH17 cells and ameliorates hepatic injury in a mouse model of chronic-binge alcohol feeding. Toxicol Lett 2016, 241:103-110

26. Wang Y, Liu Y, Sidhu A, Ma Z, McClain C, Feng W: Lactobacillus rhamnosus GG culture supernatant ameliorates acute alcohol-induced intestinal permeability and liver injury. Am J Physiol Gastrointest Liver Physiol 2012, 303:G32-G41

27. Relja B, Szermutzky M, Henrich D, Maier M, de Haan JJ, Lubbers T, Buurman WA, Marzi I: Intestinal-FABP and liver-FABP: novel markers for severe abdominal injury. Acad Emerg Med 2010, 17:729-735

28. Schellekens DH, Grootjans J, Dello SA, van Bijnen AA, van Dam RM, Dejong CH, Derikx JP, Buurman WA: Plasma intestinal fatty acid-binding protein levels correlate with morphologic epithelial intestinal damage in a human translational ischemia-reperfusion model. J Clin Gastroenterol 2014, 48:253-260

29. Steele AK, Lee EJ, Vestal B, Hecht D, Dong Z, Rapaport E, Koeppe J, Campbell TB, Wilson CC: Contribution of intestinal barrier damage, microbial translocation and HIV-1 infection status to an inflammaging signature. PLoS One 2014, 9:e97171

30. Bottasso Arias NM, Garcia M, Bondar C, Guzman L, Redondo A, Chopita N, Corsico B, Chirdo FG: Expression pattern of fatty acid binding proteins in celiac disease enteropathy. Mediators Inflamm 2015, 2015:738563

31. Cangemi R, Pignatelli P, Carnevale R, Bartimoccia S, Nocella C, Falcone M, Taliani G, Violi F; SIXTUS Study Group: Low-grade endotoxemia, gut permeability and platelet activation in communityacquired pneumonia. J Infect 2016, 73:107-114

32. Kirpich IA, Feng W, Wang Y, Liu Y, Barker DF, Barve SS, McClain CJ: The type of dietary fat modulates intestinal tight junction integrity, gut permeability, and hepatic toll-like receptor expression in a mouse model of alcoholic liver disease. Alcohol Clin Exp Res 2012, 36:835-846

33. Van De Walle J, Hendrickx A, Romier B, Larondelle Y, Schneider YJ: Inflammatory parameters in Caco-2 cells: effect of stimuli nature, concentration, combination and cell differentiation. Toxicol In Vitro 2010, 24:1441-1449

34. Chen SW, Ma YY, Zhu J, Zuo S, Zhang JL, Chen ZY, Chen GW, Wang X, Pan YS, Liu YC, Wang PY: Protective effect of 1,25dihydroxyvitamin D3 on ethanol-induced intestinal barrier injury both in vitro and in vivo. Toxicol Lett 2015, 237:79-88

35. Srinivasan B, Kolli AR, Esch MB, Abaci HE, Shuler ML, Hickman JJ: TEER measurement techniques for in vitro barrier model systems. J Lab Autom 2015, 20:107-126

36. Zhong W, McClain CJ, Cave M, Kang YJ, Zhou Z: The role of zinc deficiency in alcohol-induced intestinal barrier dysfunction. Am J Physiol Gastrointest Liver Physiol 2010, 298:G625-G633

37. Shao Y, Wolf PG, Guo S, Guo Y, Gaskins HR, Zhang B: Zinc enhances intestinal epithelial barrier function through the $\mathrm{PI} 3 \mathrm{~K} / \mathrm{AKT} / \mathrm{mTOR}$ signaling pathway in Caco-2 cells. J Nutr Biochem 2017, 43:18-26

38. Gitter AH, Bendfeldt K, Schulzke JD, Fromm M: Leaks in the epithelial barrier caused by spontaneous and TNF-alpha-induced single-cell apoptosis. FASEB J 2000, 14:1749-1753

39. Kiesslich R, Duckworth CA, Moussata D, Gloeckner A, Lim LG, Goetz M, Pritchard DM, Galle PR, Neurath MF, Watson AJ: Local barrier dysfunction identified by confocal laser endomicroscopy predicts relapse in inflammatory bowel disease. Gut 2012, 61:1146-1153

40. Li B, Zani A, Lee C, Zani-Ruttenstock E, Zhang Z, Li X, Ip W, Gonska T, Pierro A: Endoplasmic reticulum stress is involved in the colonic epithelium damage induced by maternal separation. J Pediatr Surg 2016, 51:1001-1004

41. Ringseis R, Kynast AM, Couturier A, Most E, Eder K: Ingestion of frying fat leads to activation of the endoplasmic reticulum stressinduced unfolded protein response in the duodenal mucosa of pigs. Mol Nutr Food Res 2016, 60:957-963

42. Yin P, Xu J, He S, Liu F, Yin J, Wan C, Mei C, Yin Y, Xu X, Xia Z: Endoplasmic reticulum stress in heat- and shake-induced injury in the rat small intestine. PLoS One 2015, 10:e0143922
43. Tanel A, Pallepati P, Bettaieb A, Morin P, Averill-Bates DA: Acrolein activates cell survival and apoptotic death responses involving the endoplasmic reticulum in A549 lung cells. Biochim Biophys Acta 2014, 1843:827-835

44. Kenche H, Ye ZW, Vedagiri K, Richards DM, Gao XH, Tew KD, Townsend DM, Blumental-Perry A: Adverse outcomes associated with cigarette smoke radicals related to damage to protein-disulfide isomerase. J Biol Chem 2016, 291:4763-4778

45. Kitaguchi Y, Taraseviciene-Stewart L, Hanaoka M, Natarajan R, Kraskauskas D, Voelkel NF: Acrolein induces endoplasmic reticulum stress and causes airspace enlargement. PLoS One 2012, 7:e38038

46. Logue SE, Cleary P, Saveljeva S, Samali A: New directions in ER stress-induced cell death. Apoptosis 2013, 18:537-546

47. Sano R, Reed JC: ER stress-induced cell death mechanisms. Biochim Biophys Acta 2013, 1833:3460-3470

48. Moreira AP, Texeira TF, Ferreira AB, Peluzio Mdo C, Alfenas Rde C: Influence of a high-fat diet on gut microbiota, intestinal permeability and metabolic endotoxaemia. Br J Nutr 2012, 108:801-809

49. Frazier TH, DiBaise JK, McClain CJ: Gut microbiota, intestinal permeability, obesity-induced inflammation, and liver injury. JPEN J Parenter Enteral Nutr 2011, 35:14S-20S

50. Zhou Q, Costinean S, Croce CM, Brasier AR, Merwat S, Larson SA, Basra S, Verne GN: MicroRNA 29 targets nuclear factor-kappaBrepressing factor and Claudin 1 to increase intestinal permeability. Gastroenterology 2015, 148:158-169.e8

51. Tian S, Guo R, Wei S, Kong Y, Wei X, Wang W, Shi X, Jiang H: Curcumin protects against the intestinal ischemia-reperfusion injury: involvement of the tight junction protein ZO-1 and TNF-alpha related mechanism. Korean J Physiol Pharmacol 2016, 20:147-152

52. Jang AS, Concel VJ, Bein K, Brant KA, Liu S, Pope-Varsalona H, Dopico RA Jr, Di YP, Knoell DL, Barchowsky A, Leikauf GD: Endothelial dysfunction and claudin 5 regulation during acroleininduced lung injury. Am J Respir Cell Mol Biol 2011, 44:483-490

53. Bradley MA, Markesbery WR, Lovell MA: Increased levels of 4hydroxynonenal and acrolein in the brain in preclinical Alzheimer disease. Free Radic Biol Med 2010, 48:1570-1576

54. Lovell MA, Xie C, Markesbery WR: Acrolein is increased in Alzheimer's disease brain and is toxic to primary hippocampal cultures. Neurobiol Aging 2001, 22:187-194

55. Elamin E, Masclee A, Troost F, Pieters HJ, Keszthelyi D, Aleksa K, Dekker J, Jonkers D: Ethanol impairs intestinal barrier function in humans through mitogen activated protein kinase signaling: a combined in vivo and in vitro approach. PLoS One 2014, 9:e107421

56. Su L, Nalle SC, Shen L, Turner ES, Singh G, Breskin LA, Khramtsova EA, Khramtsova G, Tsai PY, Fu YX, Abraham C, Turner JR: TNFR2 activates MLCK-dependent tight junction dysregulation to cause apoptosis-mediated barrier loss and experimental colitis. Gastroenterology 2013, 145:407-415

57. Zhu Q, Sun Z, Jiang Y, Chen F, Wang M: Acrolein scavengers: reactivity, mechanism and impact on health. Mol Nutr Food Res 2011, 55:1375-1390

58. Hamann K, Shi R: Acrolein scavenging: a potential novel mechanism of attenuating oxidative stress following spinal cord injury. J Neurochem 2009, 111:1348-1356

59. Anderson MM, Hazen SL, Hsu FF, Heinecke JW: Human neutrophils employ the myeloperoxidase-hydrogen peroxide-chloride system to convert hydroxy-amino acids into glycolaldehyde, 2-hydroxypropanal, and acrolein. A mechanism for the generation of highly reactive alpha-hydroxy and alpha,beta-unsaturated aldehydes by phagocytes at sites of inflammation. J Clin Invest 1997, 99:424-432

60. Sakata K, Kashiwagi K, Sharmin S, Ueda S, Irie Y, Murotani N, Igarashi $\mathrm{K}$ : Increase in putrescine, amine oxidase, and acrolein in plasma of renal failure patients. Biochem Biophys Res Commun 2003, 305:143-149

61. Sakata K, Kashiwagi K, Sharmin S, Ueda S, Igarashi K: Acrolein produced from polyamines as one of the uraemic toxins. Biochem Soc Trans 2003, 31:371-374 